OPEN ACCESS

Edited by:

Yuji Morita,

Aichi Gakuin University, Japan

Reviewed by:

Yaqi You,

University of Nevada, Reno, USA

Markus Seeger,

University of Zurich, Switzerland

Jennifer Karin Bender,

Robert Koch Institute, Germany

*Correspondence:

Liam J. Reynolds

Liam.reynolds.12@ucl.ac.uk

Specialty section:

This article was submitted to

Antimicrobials, Resistance

and Chemotherapy,

a section of the journal

Frontiers in Microbiology

Received: 16 July 2016 Accepted: 16 November 2016 Published: 06 December 2016

Citation:

Reynolds LJ, Roberts AP and Anjum MF (2016) Efflux in the Oral Metagenome: The Discovery of a Novel Tetracycline and Tigecycline

ABC Transporter.

Front. Microbiol. 7:1923.

doi: 10.3389/fmicb.2016.01923

\section{Efflux in the Oral Metagenome: The Discovery of a Novel Tetracycline and Tigecycline ABC Transporter}

\author{
Liam J. Reynolds ${ }^{1,2 *}$, Adam P. Roberts ${ }^{1}$ and Muna F. Anjum ${ }^{1,2}$ \\ 1 Department of Microbial Diseases, UCL Eastman Dental Institute, Faculty of Medical Sciences, University College London, \\ London, UK, ${ }^{2}$ Department of Bacteriology, Animal and Plant Health Agency, Addlestone, UK
}

Antibiotic resistance in human bacterial pathogens and commensals is threatening our ability to treat infections and conduct common medical procedures. As novel antibiotics are discovered and marketed it is important that we understand how resistance to them may arise and know what environments may act as reservoirs for such resistance genes. In this study a tetracycline and tigecycline resistant clone was identified by screening a human saliva metagenomic library in Escherichia coli EPI300 on agar containing $5 \mu \mathrm{g} / \mathrm{ml}$ tetracycline. Sequencing of the DNA insert present within the tetracycline resistant clone revealed it to contain a 7,765 bp fragment harboring novel $A B C$ half transporter genes, tet $\mathrm{AB}(60)$. Mutagenesis studies performed on these genes confirmed that they were responsible for the tetracycline and tigecycline resistance phenotypes. Growth studies performed using E. coli EPI300 clones that harbored either the wild type, the mutated, or none of these genes indicated that there was a fitness cost associated with presence of these genes, with the isolate harboring both genes exhibiting a significantly slower growth than control strains. Given the emergence of $E$. coli strains that are sensitive only to tigecycline and doxycycline it is concerning that such a resistance mechanism has been identified in the human oral cavity.

Keywords: tetracycline, tigecycline, metagenomics, $A B C$ transporter, fitness, antibiotic resistance

\section{INTRODUCTION}

Tetracyclines are a group of broad spectrum antibiotics that have recently faced a reduction in clinical use due to the increase in prevalence of tetracycline resistance (Chopra and Roberts, 2001; Bishburg and Bishburg, 2009). In the UK tetracyclines are the most sold antibiotic for animal use and represent $10 \%$ of prescribed antibiotics for human clinical use. This widespread use of tetracyclines exerts a selection pressure on microorganisms to maintain tetracycline resistance genes (Roberts, 2003; Martinez, 2009; Wu et al., 2010). Resistance is mainly attributed to the production of efflux pumps, ribosomal protection proteins (RPPs) that prevent tetracycline binding to the ribosome, and less often, tetracycline degrading enzymes (Aminov et al., 2002; Connell et al., 2003; Yang et al., 2004; Forsberg et al., 2015).

Although resistance to this group of antibiotics is prevalent they are still used in the treatment of some human infections, including Chlamydia infections and some eye infections such as trachoma (Hu et al., 2010; Dukers-Muijrers et al., 2015). Tigecycline is a novel semi-synthetic 
derivative of tetracycline and the first of the glycylcyclines. It contains a bulky $\mathrm{N}, \mathrm{N}$-dimethylglycylamido side group that allows it to overcome RPP and efflux mechanisms of resistance to earlier generation precursors such as tetracycline (Someya et al., 1995; Olson et al., 2006). Tigecycline is used in the treatment of skin and abdominal infections as well as some cases of community acquired pneumonia (Rubinstein and Vaughan, 2005; Shen et al., 2015; Van Berkel et al., 2016). It has been shown that tetracycline resistance genes can obtain mutations that broaden the activity of their products to new tetracycline derivatives (Linkevicius et al., 2015). It is important that we understand the mechanisms of resistance to our current generation of tetracyclines in order for us to identify environments that may harbor genes that could confer resistance to novel tetracyclines, including those that are still in development.

The microbiota of the human oral cavity constitutes a reservoir of tetracycline resistance genes. RPP genes such as tet $(\mathrm{M})$ are the most abundant tetracycline resistant genes in bacteria of the oral cavity (Villedieu et al., 2003; Seville et al., 2009). Tetracycline efflux genes such as major facilitator superfamily (MFS) exporters including tet(L) and the ATP Binding Cassette $(\mathrm{ABC})$ transporter tet $\mathrm{AB}(46)$ have also been detected in bacteria in the oral cavity (Lancaster et al., 2005; Seville et al., 2009; Warburton et al., 2013).

$\mathrm{ABC}$ transporters are a functionally and structurally diverse family of proteins. They may comprise a single peptide, four peptides or two half transporters. Bacterial half $\mathrm{ABC}$ transporters typically contain a transmembrane domain (TMD) and a highly conserved nucleotide binding domain (NBD). Functional dimeric $\mathrm{ABC}$ transporters are composed of two half $\mathrm{ABC}$ transporter subunits each contributing a TMD spanning the membrane to form a substrate channel (BiemansOldehinkel et al., 2006; Dawson and Locher, 2006). The two NBDs interact to form the $\mathrm{ABC}$ of the transporter at the cytoplasmic face of the membrane that can bind two ATP molecules (Jones and George, 1999). It is here that ATP binding and hydrolysis triggers conformational changes in the substrate channel (Hollenstein et al., 2007). Cycles of ATP binding and hydrolysis allow the substrate channel to alternate between being open to the cytoplasm for substrate binding and open to the cells external environment or periplasm for substrate efflux (Higgins, 2001; Hellmich et al., 2012). $\mathrm{ABC}$ transporters that confer multidrug resistance (MDR) and biocide resistance to bacteria including human pathogens have been described such as YheH/I, LmrCD, PatAB and EfrAB from Bacillus subtilis, Lactococcus lactis, Streptococcus pneumoniae and Enterococcus faecalis, respectively (Lee et al., 2003; Lubelski et al., 2004; Torres et al., 2009; Baylay et al., 2015).

The aim of this study was to identify the gene(s) conferring resistance in a tetracycline and tigecycline resistant clone that was identified from a human saliva metagenomic library in Escherichia coli. Two genes from the clone, tet $\mathrm{A}(60)$ and tet $\mathrm{B}(60)$ were found to encode for two half transporter proteins which were shown to be responsible for the observed antibiotic resistance phenotype and reduced fitness.

\section{MATERIALS AND METHODS}

\section{Strains and Culture Conditions}

The strains used in this study are listed in Table 1. E. coli EPI300 strains were cultured in Luria-Bertani broth (LB; SigmaAldrich $^{\circledR}$ ) and LB agar (LA; Life Technologies ${ }^{\mathrm{TM}}$ ) at $37^{\circ} \mathrm{C}$ with shaking at $200 \mathrm{rpm}$ for liquid culture. When antibiotic selection was required the media was supplemented with chloramphenicol $\left(12.5 \mu \mathrm{g} / \mathrm{ml}\right.$; Sigma-Aldrich $\left.{ }^{\circledR}\right)$ and tetracycline $(5 \mu \mathrm{g} / \mathrm{ml}$; SigmaAldrich $^{\circledR}$ ). Mueller Hinton (MH; Sigma-Aldrich ${ }^{\circledR}$ ) agar was used in disk diffusion assays.

\section{Sample Collection and Metagenomic DNA Extraction}

Saliva samples were collected from 11 healthy individuals who had not taken antibiotics within the previous 3 months. Saliva was expectorated into sterile tubes (approximately $5 \mathrm{ml}$ per individual) and samples were pooled. Metagenomic DNA was extracted in $1.5 \mathrm{ml}$ aliquots using a modified protocol of the Gentra Puregene Yeast/Bact. Kit (Qiagen) as previously described (Seville et al., 2009). Ethical approval to collect human saliva from volunteers was granted by the UCL Research Ethics Committee (Project ID Number 5017/001).

\section{Creation of a Metagenomic Library}

Saliva metagenomic DNA was partially digested using HindIII, ligated into pCC1BAC and transformed into E. coli EPI300 as described previously (Seville et al., 2009).

After transformation, cells were recovered in SOC media (New England Biolabs $\left.{ }^{\circledR}\right)$, cultured on LA containing chloramphenicol, $0.1 \mathrm{mM}$ isopropyl $\beta$-D-1-thiogalactopyranoside (IPTG; Promega $\left.{ }^{\odot}\right)$ and $40 \mu \mathrm{g} / \mathrm{ml}$ 5-bromo-4-chloro-3-indolyl- $\beta$-Dgalactopyranoside (X-gal; Promega ${ }^{\odot}$ ) for $16 \mathrm{~h}$. White clones were cultured in LB with chloramphenicol in individual wells of 96-well plates at $37^{\circ} \mathrm{C}$ for $16 \mathrm{~h}$. The cultures were then stored at $-80^{\circ} \mathrm{C}$ in $20 \%$ glycerol.

\section{Screening of Metagenomic Library and Resistant Clone Isolation}

Approximately 27,000 clones of the metagenomic library were screened for tetracycline resistance by plating the library onto LA with chloramphenicol $(12.5 \mu \mathrm{g} / \mathrm{ml})$ and tetracycline $(5 \mu \mathrm{g} / \mathrm{ml})$ and incubating them at $37^{\circ} \mathrm{C}$ for $16 \mathrm{~h}$. A tetracycline resistant clone, PS9, was selected for further study.

\section{DNA Sequencing, Analysis and Annotation}

A list of the primers used in this study is detailed in Supplementary Table S1. Sequencing of the BAC clone in PS9 was accomplished using 454 sequencing as described previously (Card et al., 2014). Sequencing of subclones and mutants was conducted using primer extension Sanger sequencing by Beckman Coulter Genomics Inc. Contigs were assembled using SeqMan Pro (Lasergene software, DNASTAR, Madison, WI, USA) and sequence gaps were closed using PCR and Sanger sequencing (Sanger et al., 1977). Sequences were analyzed using 
TABLE 1 | Bacterial strains, plasmids and constructs used in this study.

\begin{tabular}{|c|c|c|c|}
\hline & Name & Information & Source \\
\hline \multirow[t]{2}{*}{ Vectors } & pCC1BAC & $\begin{array}{l}\text { Chloramphenicol resistance marker, } \\
\text { inducible to multicopy in E. coli EPi300 }\end{array}$ & Epicentre $^{\circledR}$ CopyControl $^{\mathrm{TM}}$ \\
\hline & pHSG396 & Chloramphenicol resistance marker & Takara Bio $^{\odot}$ \\
\hline \multirow[t]{6}{*}{ Constructs } & pCC1BAC::PS9 & $\begin{array}{l}\text { pCC1BAC containing 7,765 bp } \\
\text { metagenomic DNA insert }\end{array}$ & This study \\
\hline & pHSG396::tetA(60) & pHSG396::tetA(60) & This study \\
\hline & pHSG396::tetB(60) & pHSG396::tetB(60) & This study \\
\hline & pHSG396::tetAB(60) & pHSG396::tetAB(60) & This study \\
\hline & pHSG396::tetB(60) $\Delta$ tetA(60) & pHSG396::tetB(60) $\Delta$ tetA(60) & This study \\
\hline & pHSG396::tetA(60) $\Delta$ tetB(60) & pHSG396::tetA(60) $\Delta$ tetB(60) & This study \\
\hline \multirow[t]{9}{*}{ Bacterial Strains } & E. coli EPI300 & $\begin{array}{l}\text { Electrocompetent, inducible trfA gene } \\
\text { for pCC1BAC copy number control }\end{array}$ & Epicentre $^{\circledR}$ CopyControl $^{\mathrm{TM}}$ \\
\hline & E. coli::pCC1BAC & E. coli EPI300::pCC1BAC & $\begin{array}{l}\text { P. Warburton, Eastman Dental } \\
\text { Institute }\end{array}$ \\
\hline & E. coli::pHSG396 & E. coli EPI300::pHSG396 & This study \\
\hline & PS9 & E. coli EPI300::[pCC1BAC::PS9] & This study \\
\hline & E. coli::pHSG396tetA(60) & E. coli EPI300::[pHSG396::tetA(60)] & This study \\
\hline & E. coli::pHSG396tetB(60) & E. coli EPI300::[pHSG396::tetB(60)] & This study \\
\hline & E. coli::pHSG396tetAB(60) & E. coli EPI300::[pHSG396::tetAB(60)] & This study \\
\hline & E. coli::pHSG396tetB(60) $\Delta$ tetA(60) & $\begin{array}{l}\text { E. coli } \\
\text { EPI300::[pHSG396::tetB(60) } \Delta \text { tetA(60)] }\end{array}$ & This study \\
\hline & E. coli::pHSG396tetA(60) $\Delta$ tetB(60) & $\begin{array}{l}\text { E. coli } \\
\text { EPI300::[pHSG396::tetA(60) } \Delta \text { tetB(60)] }\end{array}$ & This study \\
\hline
\end{tabular}

the tools on NCBI. Two open reading frames (ORFs) encoding hypothetical $\mathrm{ABC}$ half transporter genes were named tet $\mathrm{A}(60)$ and tet $\mathrm{B}(60)$ by the Stuart B. Levy lab according to tetracycline resistance gene nomenclature guidelines (Levy et al., 1999). The sequences for tet $\mathrm{A}(60)$ and $\operatorname{tet} \mathrm{B}(60)$ were submitted to GenBank (accession numbers KX000272.1 and KX000273.1). The full 7,765 bp insert sequence was also submitted to Genbank (accession number KX887332; Supplementary Figure S1C). The putative amino acid sequences of $\operatorname{Tet} \mathrm{A}(60)$ and $\operatorname{Tet} \mathrm{B}(60)$ were compared to other phenotypically validated tetracycline and multidrug $A B C$ transporter protein sequences from Grampositive bacteria [TetAB(60), YheH/I, LmrCD, PatAB and EfrAB] by alignment using Clustal Omega at http://www.ebi.ac.uk/ Tools/msa/clustalo/.

\section{Subcloning}

Primers used for subcloning are detailed in Supplementary Table S1. Regions of PS9 were amplified using primer pairs that introduced flanking HindIII and BamHI sites. The amplified fragments were ligated into pHSG396 and transformed into E. coli EPI300.

\section{Mutagenesis}

Primers used for mutagenesis are listed in Supplementary Table S1. In frame deletions of the Walker-A motifs of tet $\mathrm{A}(60)$ and tet $\mathrm{B}(60)$ were made using the NEB Q5 Site Directed Mutagenesis kit. Two pairs of non-overlapping primers were designed to amplify the pHSG396 vector containing both transporter genes. The first primer pair amplified pHSG396::tet $\mathrm{AB}(60)$ without a $69 \mathrm{bp}$ region containing the tet $\mathrm{A}(60)$ Walker-A motif, keeping tet $\mathrm{B}(60)$ full length. The second primer pair amplified pHSG396::tet $\mathrm{AB}(60)$ without a $57 \mathrm{bp}$ region containing the Walker-A motif of tet $\mathrm{B}(60)$ keeping tet $\mathrm{A}(60)$ intact. The resulting PCR products were circularized and transformed into E. coli EPI300.

\section{Disk Diffusion Assays}

The susceptibilities of E. coli EPI300, E. coli::pHSG396 and E. coli::pHSG396tetAB(60) to various antibiotics (cefotaxime, ceftazidime metronidazole, neomycin, ciprofloxacin, nalidixic acid, gentamicin, amikacin, amoxicillin/clavulanate and trimetoprim/sulfametoxazole and erythromycin) were evaluated using the disk diffusion assay according to BSAC guidelines (Andrews, 2001). The antibiotic disks and concentrations used in this study are listed in Table 2.

\section{Minimum Inhibitory Concentration (MIC) Assays}

Minimum Inhibitory Concentrations of tetracycline, minocycline, and tigecycline were determined using the microbroth dilution method according to European Committee on Antimicrobial Susceptibility Testing (EUCAST) guidelines (EUCAST, 2015). For MIC determination, overnight cultures grown in $\mathrm{LB}$ were adjusted to an $\mathrm{OD}_{600}$ of $0.1 ; 10 \mu \mathrm{l}$ of the adjusted overnight cultures were used to inoculate $90 \mu \mathrm{l}$ fresh LB containing varying concentrations of tetracycline $(0.25-32 \mu \mathrm{g} / \mathrm{ml})$, minocycline $(0.25-10 \mu \mathrm{g} / \mathrm{ml})$ or tigecycline $(0.25-10 \mu \mathrm{g} / \mathrm{ml})$ in a 96 well plate format. These plates were incubated overnight at $37^{\circ} \mathrm{C}$ with shaking at $200 \mathrm{rpm}$. Growth was determined by spectrophotometry at $\mathrm{OD}_{600}$ and the MIC 
TABLE 2 | List of antibiotic disks used.

\begin{tabular}{lc}
\hline $\begin{array}{l}\text { Antibiotic } \\
\text { (Concentration) }\end{array}$ & Concentration \\
\hline Cefotaxime & $30 \mu \mathrm{g}$ \\
Metronidazole & $50 \mu \mathrm{g}$ \\
Neomycin & $10 \mu \mathrm{g}$ \\
Ciprofloxacin & $1 \mu \mathrm{g}$ \\
Nalidixic acid & $30 \mu \mathrm{g}$ \\
Gentamicin & $10 \mu \mathrm{g}$ \\
Amoxicillin/Clavulanate & $20 \mu \mathrm{g} / 10 \mu \mathrm{g}$ \\
Trimetoprim/Sulfametoxazole & $23.75 \mu \mathrm{g} / 1.25 \mu \mathrm{g}$ \\
Amikacin & $30 \mu \mathrm{g}$ \\
Tetracycline & $10 \mu \mathrm{g}$ \\
Ceftazidime & $30 \mu \mathrm{g}$ \\
Erythromycin & $5 \mu \mathrm{g}$ \\
\hline
\end{tabular}

was determined as the lowest concentration of antibiotic that inhibited growth.

\section{Growth Curves}

Overnight cultures of E. coli::pHSG396, E. coli::pHSG396tet$\mathrm{AB}(60)$, E. coli::pHSG396tet $\mathrm{B}(60) \Delta$ tet $\mathrm{A}(60)$ and $E$. coli::pHSG396 tet $\mathrm{A}(60) \Delta$ tet $\mathrm{B}(60)$ grown in $\mathrm{LB}$ with chloramphenicol (12.5 $\mu \mathrm{g} / \mathrm{ml})$ and tetracycline $(5 \mu \mathrm{g} / \mathrm{ml}$; when required) were adjusted to an $\mathrm{OD}_{600}$ of 0.05 in $\mathrm{LB}$ and chloramphenicol $(12.5 \mu \mathrm{g} / \mathrm{ml})$. Cell suspensions were grown at $37^{\circ} \mathrm{C}$ with shaking at $200 \mathrm{rpm}$ for $7 \mathrm{~h}$ and their cell density was measured every 30 min using spectrophotometry $\left(\mathrm{OD}_{600}\right)$. E. coli::pHSG396tet$\mathrm{AB}(60)$ was also grown in $\mathrm{LB}$ and chloramphenicol $(12.5 \mu \mathrm{g} / \mathrm{ml})$ with tetracycline $(5 \mu \mathrm{g} / \mathrm{ml})$ to determine if the presence of this antibiotic affected the clones. Growth rates were measured for each clone as the slope of the line between two time points on the growth curve. The equation $\mathrm{N}_{\mathrm{t}}=\mathrm{N}_{0}^{*}(1+\mathrm{r})^{\mathrm{t}}$, was used to calculate the maximum growth rate between 60 and $240 \mathrm{~min}$. Technical triplicates and biological triplicates were conducted for all growth curves and growth rate calculations.

\section{Statistical Analysis}

Standard deviations were calculated for each clone using the data obtained from the growth curve assays, which included nine data points encompassing biological and technical replicates. Standard deviations were used as error bars in Figure 2 for comparison of the mean $\mathrm{OD}_{600}$ for each clone. Two tailed $t$-tests with $95 \%$ confidence intervals were used to determine the significance of differences between clones and the control (E. coli::pHSG396) in terms of $\mathrm{OD}_{600}$ at $420 \mathrm{~min}$ and growth kinetics.

\section{RESULTS}

A library of 27,000 clones was constructed from the pooled human saliva of 11 individuals. Screening of this metagenomic library for tetracycline resistant clones resulted in the isolation of two of clones capable of growing on tetracycline $(5 \mu \mathrm{g} / \mathrm{ml})$, including PS9.
Analysis of the 7,765 bp PS9 insert revealed it to have nucleotide similarity along its entire length with Streptococcus sp. 263_SSPC (accession: GCA_001071995.1, 98\% cover and 90\% identity) and Granulicatella adiacens ATCC 49175 (accession: NZ_ACKZ00000000, 94\% cover and 92\% identity). The alignments also identified an inversion in the PS9 insert between 1,600 bp and 1,789 bp (Supplementary Figures S1A,B). BlastX analysis of the insert predicted it to contain five putative ORFs (Figure 1A). The hypothetical products of the five ORFs had a homolog with $>90 \%$ amino acid identity from Streptococcus sp. 263_SSPC and G. adiacens ATCC 49175. Of the ORFs identified, three encoded a UDP-galactose mutase, sulfurtransferase and amidohydrolase. The remaining ORFs were predicted to encode two half ABC transporters that were named TetA(60) and TetB(60) as their putative amino acid sequences had less than $80 \%$ similarity to any other tetracycline resistance protein amino acid sequence and therefore fulfilled the criteria for a new tetracycline resistance gene. Interestingly, in the Streptococcus sp. 263_SSPC genome sequence two transposase genes were found $634 \mathrm{bp}$ and 6,196 bp upstream of the UDP-galactose mutase. No such genes were identified in the G. adiacens ATCC 49175 genome. Clustal Omega alignments of the putative amino acid sequences of $\operatorname{Tet} \mathrm{A}(60)$ and $\operatorname{Tet} \mathrm{B}(60)$ to characterized antibiotic resistance heterodimeric $\mathrm{ABC}$ transporters showed that they were more closely related to TetA(46) and TetB(46) $(39.27 \%$ and $42.28 \%$ identity, respectively) and YheH and YheI (40.93\% and $46.61 \%$, respectively). Tet $\mathrm{AB}(60)$ were less related to the MDR ABC transporters EfrAB, PatAB and LmrCD of E. faecalis, S. pneumoniae and L. lactis, respectively ( $\leq 34.46 \%)$, Table 3.

Each putative $\mathrm{ABC}$ half transporter peptide was predicted to be 579 amino acids and both contained a predicted NBD and a TMD, which are hallmarks of ABC transporters. Additionally, there is a 4 bp overlap of the genes, with the start codon of tet $\mathrm{B}(60)$ being contained within tet $\mathrm{A}(60)$, although the genes are in different reading frames.

To determine if these two genes were responsible for the observed tetracycline resistance phenotype of PS9, tetA(60) and tet $\mathrm{B}(60)$ were individually and jointly subcloned into E. coli EPI300 using the pHSG396 cloning vector. Only E. coli::pHSG396tet $\mathrm{AB}(60)$ grew on $5 \mu \mathrm{g} / \mathrm{ml}$ of tetracycline, showing that both $\operatorname{tet} \mathrm{A}(60)$ and $\operatorname{tet} \mathrm{B}(60)$ were required for the tetracycline resistance.

In order to ascertain whether the gene products function as a heterodimeric $\mathrm{ABC}$ transporter that confers resistance to tetracycline, a 69 and 57 base pair deletion was made to remove the Walker A motif of the NBD from either tet $\mathrm{A}(60)$ or tet $\mathrm{B}(60)$, respectively (Figure 1B). Both mutants, E. coli::pHSG396 tet $\mathrm{B}(60) \Delta$ tet $\mathrm{A}(60)$ and $E$. coli::pHSG396tet $\mathrm{A}(60) \Delta$ tet $\mathrm{B}(60)$ were susceptible to tetracycline. This confirmed that the $\mathrm{ABC}$ transporter activity of these gene products is responsible for the tetracycline resistance in PS9 and the E. coli::pHSG396tetAB(60), Table 4.

Using the broth dilution method, the MIC of tetracycline for E. coli EPI300, E. coli::pHSG396, E. coli::pHSG396tetAB(60), E. coli::pHSG396tetB(60) $\Delta$ tetA(60) and E. coli::pHSG396 tet $\mathrm{A}(60) \Delta$ tet $\mathrm{B}(60)$ was determined (Table 4 ). The MIC of tetracycline for E. coli::pHSG396tetAB(60) was found to be 
A

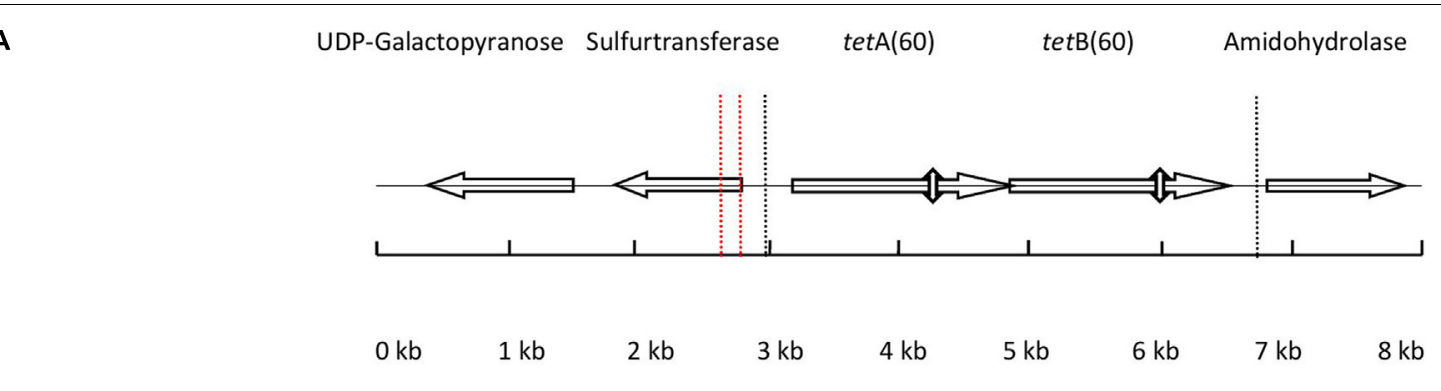

B

tetB(60) $\Delta t e t \mathrm{~A}(60)$

Nucleotide 5 '-ACGCTTGGAATCGTTGGAAAAACGGGTTCTGGGAAGACGACGCTCTTGATGCAATTATTACATCAATTT-3' (4220-4288)

Amino Acid N-GKTGCGKTTL-C

$\operatorname{tet} \mathrm{A}(60) \Delta \operatorname{tet} \mathrm{B}(60)$

Nucleotide $\quad$ 5'-GTTGCTITTGTCGGACATACTGGTTCAGGGAAATCATCCATTATGAACTTACTGTTT-3' (5974-6030)

Amino Acid N-GHTGSGKSSI-C

FIGURE 1 | (A) Diagram depicting the position and orientation of the ORFs present in the 7,765 base pair insert of PS9 according to BlastX. The 3, 703 base pair region containing tetAB(60) that were subcloned to create pHSG396::tetAB(60) is marked by dashed lines. The positions of the Walker $A$ motifs that were deleted to make pHSG396::tetB(60) $\Delta$ tetA(60) and pHSG396::tetA(60) $\Delta$ tetB(60) are marked by vertical double headed arrows and the inversion in the sequence is indicated by vertical dashed red lines. (B) The nucleotide sequences of the deleted regions are given above with the Walker A motif of each gene underlined and translated.

TABLE 3 | Alignment of TetAB(60) to other antibiotic resistance $A B C$ transporters.

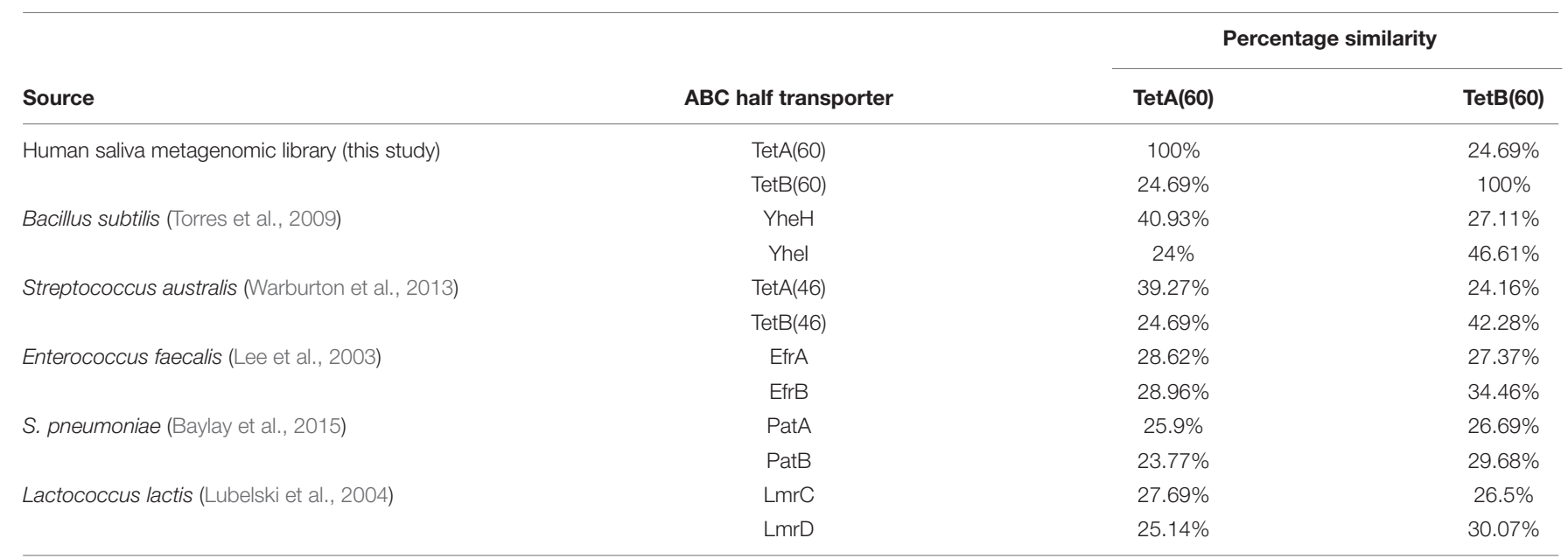

$32 \mu \mathrm{g} / \mathrm{ml}$. The MICs for the mutants and the controls strains were 16 -fold lower at $2 \mu \mathrm{g} / \mathrm{ml}$. To determine if tet $\mathrm{AB}(60)$ was able to confer resistance to later generation tetracycline derivatives, MIC assays were conducted using minocycline and tigecycline. The MIC of minocycline for all strains and clones was $1 \mu \mathrm{g} / \mathrm{ml}$. The MIC of tigecycline for E. coli::pHSG396tetAB(60) was 16 -fold higher than the control and mutant strains at $8 \mu \mathrm{g} / \mathrm{ml}$, which was above the clinical break point for Enterobacteriaceae $(0.5 \mu \mathrm{g} / \mathrm{ml})$.

Disk diffusion assays were used to discern the spectrum of resistance for this transporter. E. coli::pHSG396tetAB(60) was less sensitive to tetracycline but equally sensitive to cefotaxime, ceftazidime, metronidazole, neomycin, ciprofloxacin, nalidixic acid, gentamicin, amikacin, amoxicillin/clavulanate and trimetoprim/sulfametoxazole as E. coli EPI300 and E. coli::pHSG396. E. coli EPI300 was intrinsically resistant to erythromycin which has been described previously and attributed to AcrAB-TolC mediated efflux and membrane impermeability (Vaara, 1993; Chollet et al., 2004).

We observed, when it was first isolated, that PS9 grew slower and formed smaller colonies than E. coli::pCC1BAC even in the absence of tetracycline in the growth media; this phenotype 
TABLE 4 | MICs of tetracycline antibiotics for E. coli::pHSG396tetAB(60) and mutant strains.

\begin{tabular}{lccc}
\hline Strain & $\begin{array}{c}\text { Tetracycline } \\
(\boldsymbol{\mu} \mathbf{g} / \mathbf{m l})\end{array}$ & $\begin{array}{c}\text { Minocycline } \\
(\boldsymbol{\mu} \mathbf{g} / \mathbf{m l})\end{array}$ & $\begin{array}{c}\text { Tigecycline } \\
(\boldsymbol{\mu} \mathbf{g} / \mathbf{m l})\end{array}$ \\
\hline E. coli::pHSG396 & 2 & 1 & 0.5 \\
E. coli::pHSG396tetAB(60) & 32 & 1 & 8 \\
E. coli::pHSG396tetB(60) $\Delta$ tetA(60) & 2 & 1 & 0.5 \\
E. coli::pHSG396tetA(60) $\Delta$ tetB(60) & 2 & 1 & 0.5 \\
\hline
\end{tabular}

was also observed for the E. coli::pHSG396tetAB(60) subclone. Furthermore, it was noted that the E. coli::pHSG396tetB(60)$\Delta$ tet $\mathrm{A}(60)$ and $E$. coli::pHSG396tet $\mathrm{A}(60) \Delta$ tet $\mathrm{B}(60)$ mutants did not have such a large growth defect. Growth curves revealed that although there were significant differences between E. coli::pHSG396 and E. coli::pHSG396tetA(60) $\Delta$ tet $\mathrm{B}(60)$ maximum growth rates $(0.993 \pm 0.05$ and $0.917 \pm 0.05$, respectively; $\mathrm{p}=0.005)$ there was no significant difference in their $\mathrm{OD}_{600}$ of cultures at $7 \mathrm{~h}(1.65 \pm 0.08$ and $1.565 \pm 0.16$; $\mathrm{p}=0.1807$ ) when grown in the absence of tetracycline (Figure 2).

Compared to E. coli::pHSG396, E. coli::pHSG396tetB(60) $\Delta$ tet $\mathrm{A}(60)$ and $E$. coli::pHSG396tet $\mathrm{AB}(60)$ reached lower $\mathrm{OD}_{600}$ at $7 \mathrm{~h}$ when they were grown in the absence of tetracycline (0.983 $\pm 0.03,0.733 \pm 0.01$, respectively, $\mathrm{p}<0.0001)$. Additionally, when grown in the presence of tetracycline, E. coli::pHSG396tet $\mathrm{AB}(60)$ reached an even lower $\mathrm{OD}_{600}$ at $7 \mathrm{~h}(0.543 \pm 0.04, \mathrm{p}<0.0001)$. Whilst the maximum growth rates of $E$. coli::pHSG396tetB(60) $\Delta$ tet $\mathrm{A}(60)$ grown without tetracycline and $E$. coli::pHSG396tet $\mathrm{AB}(60)$ grown without or with tetracycline were not significantly different from each other $(0.702 \pm 0.06,0.68 \pm 0.03$ and $0.692 \pm 0.09$, respectively; $\mathrm{p}=0.435$ to 0.879 ), they were $1.14-1.46$ fold lower than the maximum growth rate of $E$. coli::pHSG396 grown without tetracycline $(\mathrm{p}<0.0001)$. We therefore suggest that there is a fitness cost due to the activity of $\operatorname{Tet} \mathrm{AB}(60)$ rather than the carriage of the plasmid itself and that $\operatorname{TetB}(60)$ contributes more to this fitness cost than $\operatorname{Tet} \mathrm{A}(60)$.

\section{DISCUSSION}

There has been a resurgence in the use of tetracyclines in human therapy due to the recent development of a number of semisynthetic derivatives of the antibiotic that are efficacious against antibiotic resistant pathogens (Rubinstein and Vaughan, 2005; Anstead et al., 2014; Shen et al., 2015; Lin et al., 2016; Van Berkel et al., 2016). Tigecycline is the first of this new generation of tetracyclines to enter clinical use, being effective against MDR pathogens including carbapenem and colistin resistant microorganisms and those expressing specific tetracycline efflux systems and RPPs (Fluit et al., 2005; Cai et al., 2011). However, it is worrisome that resistance to tigecycline has already been described and associated with multidrug efflux systems and ribosomal mutations (Villa et al., 2014; Zhong et al., 2014; Lupien et al., 2015).

In this study we characterized a clone, PS9, isolated from a human oral saliva metagenomic library that exhibited high levels of resistance to tetracycline and tigecycline. BlastN alignments of the clone with Streptococcus sp. 263_SSPC and G. adiacens ATCC 49175 revealed the PS9 insert to have 90\% and 92\% nucleotide similarity to these species, respectively, indicating a probable Gram-positive origin for the insert. Streptococcus spp. are predominant in the oral cavity although to the best of our knowledge Streptococcus sp. 263_SSPC has not been identified (Segata et al., 2012). Granulicatella spp. including G. adiacens are also abundant in the oral cavity, typically inhabiting the mucosa (Aas et al., 2005). Tetracycline resistance mediated by Tn916 encoded tet(M) has been described for

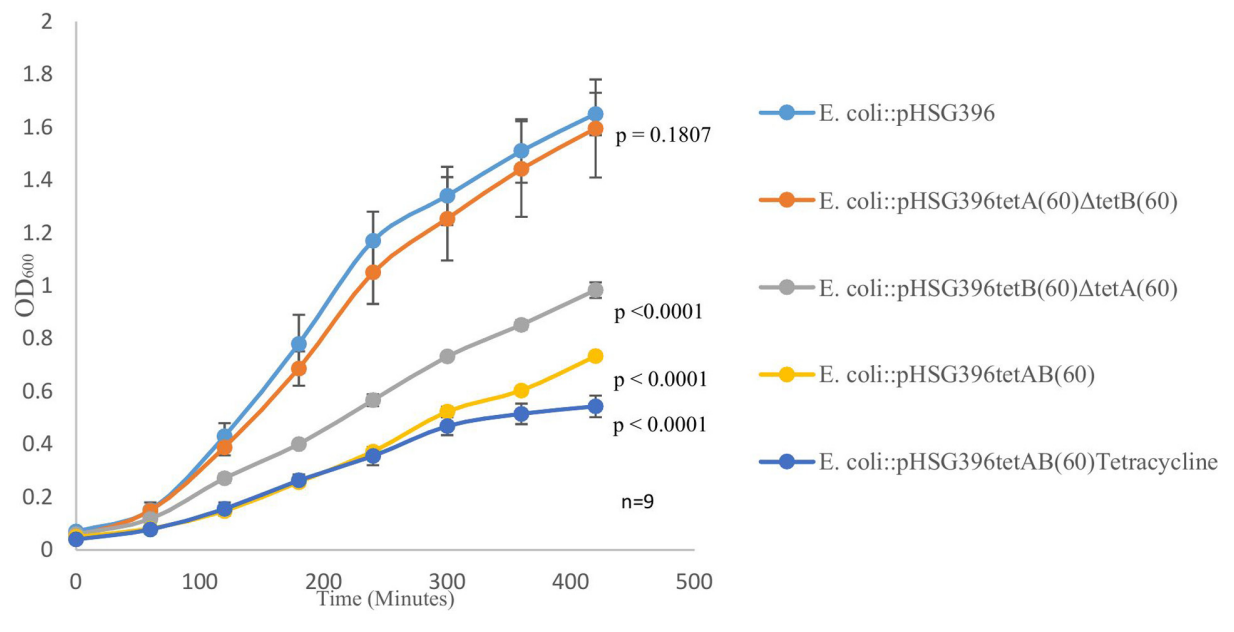

FIGURE 2 | The above graph depicts growth curves for E. coli::pHSG396, E. coli::pHSG396tetB(60) $\Delta$ tetA(60) and E. coli::pHSG396tetA(60) $\Delta$ tetB(60) grown in LB and chloramphenicol for $\mathbf{7} \mathbf{h}$. It also shows the growth curve for E. coli::pHSG396tetAB(60) grown in LB and chloramphenicol with and without tetracycline to determine how the antibiotic effected the clone's growth. $P$-values for $\mathrm{OD}_{600}$ at $7 \mathrm{~h}$ were calculated from biological triplicate $\mathrm{OD}_{600}$ measurements at 420 min for each clone compered to E. coli::pHSG396 are indicated beside each growth curve. 
oral Streptococcus and Granulicatella spp. (Lancaster et al., 2005). Additionally, MFS and ABC transporter genes conferring resistance to tetracyclines have also been identified in oral Streptococcus spp. including tet $(\mathrm{L})$ and tet $\mathrm{AB}(46)$, respectively (Chen et al., 2013; Warburton et al., 2013). Although tetracycline resistance has been observed in Granulicatella spp., minimal characterisation studies have been conducted (Zheng et al., 2004; De Luca et al., 2013). Although Streptococcus and Granulicatella spp. are abundant in the oral cavity, it is not known how prevalent tet $\mathrm{AB}(60)$ is in the oral cavity and further work beyond the scope of our characterisation study is required to address this.

Two transposase genes were located up stream of the UDPgalactose mutase gene in Streptococcus sp. 263_SSPC, however, it is unknown if these transposases are found in the host genome of the PS9 sequence or if they are capable of transposition of tet $\mathrm{AB}(60)$. The alignments also identified an inverted region in the PS9 insert when compared to the Streptococcus sp. 263_SSPC and G. adiacens ATCC 49175 genomes which may have resulted from a DNA breakage followed by repair or a transposition event.

Analysis of the insert revealed it contained five ORFs, predicted to encode a putative UDP-galactose mutase, a sulfurtransferase, an amidohydrolase and two $A B C$ half transporters. Each predicted protein had amino acid sequences with high similarity ( $>90 \%$ identity) to proteins from Streptococcus sp. 263_SSPC and G. adiacens. Numerous heterodimeric $\mathrm{ABC}$ transporters capable of conferring antibiotic resistance have been described, including the MDR transporters EfrAB of E. faecalis (Lee et al., 2003), PatAB from S. pneumoniae (Baylay et al., 2015), LmrCD from L. lactis (Lubelski et al., 2004) and the recently characterized EfrCD of E. faecalis (Hurlimann et al., 2016). These transporters have been shown to confer resistance to fluoroquinolones, tetracyclines and biocides among other antimcrobials. Alignment of the putative amino acid sequences of $\operatorname{Tet} \mathrm{AB}(60)$ to other antibiotic resistance heterodimeric $\mathrm{ABC}$ transporters showed that they were most closely related to TetAB(46) and YheH/I and less so to the MDR ABC transporters EfrAB, PatAB and LmrCD. As TetAB(46) has been shown to be most closely related to $\mathrm{YheH} / \mathrm{I}$ this suggested that $\operatorname{Tet} A B(60)$ was also tetracycline specific (Warburton et al., 2013).

We showed that both $\operatorname{tet} \mathrm{A}(60)$ and $\operatorname{tet} \mathrm{B}(60)$ were required to confer tetracycline resistance in E. coli EPI300, suggesting that the product of these genes formed a heterodimeric $A B C$ transporter with each gene product containing a TMD and NBD as revealed by BlastX (Dawson and Locher, 2006). Previous studies have used E. coli as a host to characterize Gram-positive antimicrobial $\mathrm{ABC}$ transporters including $\mathrm{E} f \mathrm{AB}$ from $E$. faecalis and LmrA from L. lactis (Lee et al., 2003; Achard-Joris et al., 2005). As E. coli::pHSG396tetAB(60) did not contain the inverted sequence it is likely that this sequence does not affect expression of tet $\mathrm{AB}(60)$.

Walker A motifs are found in many ATP utilizing enzymes including $\mathrm{ABC}$ transporters and are required for binding and stabilizing ATP (Ramakrishnan et al., 2002). Deletion of these motifs from ATP transporters has been shown to result in a loss of function (Warburton et al., 2013). Individual in-frame deletions of these motifs from either $\operatorname{tet} \mathrm{A}(60)$ or tet $\mathrm{B}(60)$ led to a loss of the tetracycline and tigecycline resistance phenotype providing further evidence that the products of these genes form a heterodimeric $\mathrm{ABC}$ transporter.

Compared to E. coli::pHSG396, E. coli::pHSG396tetAB(60) was 16-fold more resistant to tetracycline (MIC of $32 \mu \mathrm{g} / \mathrm{ml}$ ) and tigecycline (MIC of $8 \mu \mathrm{g} / \mathrm{ml}$ ). Although E. coli::pHSG396tet $\mathrm{AB}(60)$ showed levels of resistance to tetracycline and tigecycline beyond the EUCAST breakpoints, it was as susceptible to minocycline as E. coli::pHSG396, indicating that minocycline is not a substrate for this transporter (Olson et al., 2006; Ramos et al., 2009). Efflux mediated tigecycline resistance has been described previously in Pseudomonas aeruginosa and Klebsiella pneumoniae, being attributed to the activity of an $\mathrm{ABC}$ and a resistance nodulation division (RND) transporter, respectively (Dean et al., 2003; He et al., 2015; McDaniel et al., 2016). TetAB(46) was also shown to confer low tigecycline resistance in S. australis (Warburton et al., 2013).

$\operatorname{Tet} \mathrm{AB}(60)$ appeared to be specific for tetracycline and tigecycline as disk diffusion assays demonstrated E. coli::pHSG396 to be as susceptible as E. coli::pHSG396tetAB(60) to cefotaxime, ceftazidime, metronidazole, neomycin, ciprofloxacin, nalidixic acid, gentamicin, amikacin, amoxicillin/clavulanate and trimetoprim/sulfametoxazole and erythromycin, providing further evidence for the tetracycline specificity of the $A B C$ transporter.

The observed fitness cost associated with tet $\mathrm{AB}(60)$ was not observed in either mutant as although E. coli::pHSG396tetA(60) $\Delta$ tet $\mathrm{B}(60)$ had a lower maximum growth rate than the control it had a comparable final $\mathrm{OD}_{600}$ to E. coli::pHSG396 and E. coli::pHSG396tetB(60) $\Delta$ tet $\mathrm{A}(60)$ exhibited faster growth than E. coli::pHSG396tet AB(60). This indicated that the growth defect was a result of $\operatorname{Tet} \mathrm{AB}(60)$ activity rather than from maintenance of the plasmid. Additionally, as E. coli::pHSG396 tet $\mathrm{B}(60) \Delta$ tet $\mathrm{A}(60)$ grew less well than E. coli::pHSG396tet $\mathrm{A}(60) \Delta$ tet $\mathrm{B}(60)$ it suggests that $\mathrm{Tet} \mathrm{B}(60)$ produces a greater cost to the E. coli host than TetA(60).

\section{CONCLUSION}

We have identified two novel genes from the human oral cavity that likely produce a heterodimeric $\mathrm{ABC}$ transporter, Tet $A B(60)$. Tet $A B(60)$ specifically exports tetracycline and tigecycline conferring high levels of resistance to these antibiotics in an E. coli host. A limitation of this work is that we do not know the prevalence of these genes in the human oral cavity. Further work should be undertaken to survey its prevalence in various niches, to determine how common these genes are, and their possible clinical relevance for treating bacterial infections with tetracycline derivatives. This work also shows that the human oral cavity harbors unknown tetracycline resistance determinants in the absence of any obvious selection pressure. There is potential for these genes to be acquired by mobile genetic elements and transferred to bacterial pathogens, which is particularly worrying given the recent identification of a carbapenem and colistin 
resistant strains of $E$. coli some of which could only be inhibited by doxycycline and tigecycline (Liu et al., 2016; Mediavilla et al., 2016; Yao et al., 2016). However, the associated fitness cost of tet $\mathrm{AB}(60)$ observed in E. coli may limit any possible fixation following dissemination of the genes from their native host to E. coli strains in the absence of a tetracycline or tigecycline selective pressure.

\section{AUTHOR CONTRIBUTIONS}

LR contributed to the design of the experiments as well as to the acquisition, analysis, interpretation of the data included in this manuscript, wrote initial and revised drafts of the manuscript and approves of the final manuscript being submitted and also agrees to be accountable for the work detailed in the submitted manuscript. AR conceived the project, contributed to the design of experiments conducted throughout it, interpreted results and contributed to the drafting and revising of the manuscript being submitted and also approved the final draft of the manuscript and agrees to be accountable for the work detailed in the submitted manuscript. MA conceived the project, contributed to the design and direction of experiments within it, interpreted results and made revisions to the final manuscript, approved the manuscript

\section{REFERENCES}

Aas, J. A., Paster, B. J., Stokes, L. N., Olsen, I., and Dewhirst, F. E. (2005). Defining the normal bacterial flora of the oral cavity. J. Clin. Microbiol. 43, 5721-5732. doi: 10.1128/JCM.43.11.5721-5732.2005

Achard-Joris, M., van den Berg van Saparoea, H. B., Driessen, A. J. M., and Bourdineaud, J.-P. (2005). Heterologously expressed bacterial and human multidrug resistance proteins confer cadmium resistance to Escherichia coli. Biochemistry 44, 5916-5922. doi: 10.1021/bi047700r

Aminov, R. I., Chee-Sanford, J. C., Garrigues, N., Teferedegne, B., Krapac, I. J., White, B. A., et al. (2002). Development, validation, and application of PCR primers for detection of tetracycline efflux genes of gram-negative bacteria. Appl. Environ. Microbiol. 68, 1786-1793. doi: 10.1128/AEM.68.4.1786-1793. 2002

Andrews, J. M. (2001). BSAC standardized disc susceptibility testing method. J Antimicrob Chemother. 48(Suppl. 1), 43-57. doi: 10.1093/jac/48. 2.322

Anstead, G. M., Cadena, J., and Javeri, H. (2014). Treatment of infections due to resistant Staphylococcus aureus. Methods Mol. Biol. 1085, 259-309. doi: 10.1007/978-1-62703-664-1_16

Baylay, A. J., Ivens, A., and Piddock, L. J. (2015). A novel gene amplification causes upregulation of the PatAB $\mathrm{ABC}$ transporter and fluoroquinolone resistance in Streptococcus pneumoniae. Antimicrob. Agents Chemother. 59, 3098-3108. doi: 10.1128/AAC.04858-14

Biemans-Oldehinkel, E., Doeven, M. K., and Poolman, B. (2006). ABC transporter architecture and regulatory roles of accessory domains. FEBS Lett. 580, $1023-$ 1035. doi: 10.1016/j.febslet.2005.11.079

Bishburg, E., and Bishburg, K. (2009). Minocycline-an old drug for a new century: emphasis on methicillin-resistant Staphylococcus aureus (MRSA) and Acinetobacter baumannii. Int. J. Antimicrob. Agents 34, 395-401. doi: 10.1016/j. ijantimicag.2009.06.021

Cai, Y., Wang, R., Liang, B., Bai, N., and Liu, Y. (2011). Systematic review and meta-analysis of the effectiveness and safety of tigecycline for treatment of infectious disease. Antimicrob. Agents Chemother. 55, 1162-1172. doi: 10.1128/ AAC.01402-10

Card, R. M., Warburton, P. J., MacLaren, N., Mullany, P., Allan, E., and Anjum, M. F. (2014). Application of microarray and functional-based screening being submitted and also agrees to be accountable for the work represented in the submitted manuscript.

\section{FUNDING}

LR was jointly funded by the Seedcorn Programme at the Animal and Plant Health Agency and a UCL IMPACT studentship at UCL.

\section{ACKNOWLEDGMENT}

We would like thank Mr. Supathep Tansirichaiya (UCL) for providing us with the human saliva metagenomic DNA used in this study and Dr. Philip J. Warburton (University of Plymouth) for providing us with E. coli EPI300::pCC1BAC.

\section{SUPPLEMENTARY MATERIAL}

The Supplementary Material for this article can be found online at: http://journal.frontiersin.org/article/10.3389/fmicb. 2016.01923/full\#supplementary-material

methods for the detection of antimicrobial resistance genes in the microbiomes of healthy humans. PLoS ONE 9:e86428. doi: 10.1371/journal.pone.0086428

Chen, L., Song, Y., Wei, Z., He, H., Zhang, A., and Jin, M. (2013). Antimicrobial susceptibility, tetracycline and erythromycin resistance genes, and multilocus sequence typing of Streptococcus suis isolates from diseased pigs in China. J. Vet. Med. Sci. 75, 583-587. doi: 10.1292/jvms.12-0279

Chollet, R., Chevalier, J., Bryskier, A., and Pagès, J.-M. (2004). The AcrABTolC pump is involved in macrolide resistance but not in telithromycin efflux in Enterobacter aerogenes and Escherichia coli. Antimicrob. Agents Chemother. 48, 3621-3624. doi: 10.1128/AAC.48.9.3621-3624. 2004

Chopra, I., and Roberts, M. (2001). Tetracycline antibiotics: mode of action, applications, molecular biology, and epidemiology of bacterial resistance. Microbiol. Mol. Biol. Rev. 65, 232-260. doi: 10.1128/MMBR.65.2. 232-260.2001

Connell, S. R., Tracz, D. M., Nierhaus, K. H., and Taylor, D. E. (2003). Ribosomal protection proteins and their mechanism of tetracycline resistance. Antimicrob. Agents Chemother. 47, 3675-3681. doi: 10.1128/AAC.47.12. 3675-3681.2003

Dawson, R. J., and Locher, K. P. (2006). Structure of a bacterial multidrug ABC transporter. Nature 443, 180-185. doi: 10.1038/nature05155

De Luca, M., Amodio, D., Chiurchiu, S., Castelluzzo, M. A., Rinelli, G., Bernaschi, P., et al. (2013). Granulicatella bacteraemia in children: two cases and review of the literature. BMC Pediatr. 13:61. doi: 10.1186/14712431-13-61

Dean, C. R., Visalli, M. A., Projan, S. J., Sum, P.-E., and Bradford, P. A. (2003). Efflux-mediated resistance to tigecycline (GAR-936) in Pseudomonas aeruginosa PAO1. Antimicrob. Agents Chemother. 47, 972-978. doi: 10.1128/ AAC.47.3.972-978.2003

Dukers-Muijrers, N. H., van Liere, G. A., Wolffs, P. F., Den Heijer, C., Werner, M. I., and Hoebe, C. J. (2015). Antibiotic use before chlamydia and gonorrhea genital and extragenital screening in the sexually transmitted infection clinical setting. Antimicrob. Agents Chemother. 59, 121-128. doi: 10.1128/aac. 03932-14

EUCAST (2015). Breakpoint Tables for Interpretation of MICs and Zone Diameters. Version 5.0, 2015. Basel: European Committee on Antimicrobial Susceptibility Testing. Available at: http://www.eucast.org 
Fluit, A. C., Florijn, A., Verhoef, J., and Milatovic, D. (2005). Presence of tetracycline resistance determinants and susceptibility to tigecycline and minocycline. Antimicrob. Agents Chemother. 49, 1636-1638. doi: 10.1128/aac. 49.4.1636-1638.2005

Forsberg, K. J., Patel, S., Wencewicz, T. A., and Dantas, G. (2015). The tetracycline destructases: a novel family of tetracycline-inactivating enzymes. Chem. Biol. 22, 888-897. doi: 10.1016/j.chembiol.2015.05.017

He, F., Fu, Y., Chen, Q., Ruan, Z., Hua, X., Zhou, H., et al. (2015). Tigecycline susceptibility and the role of efflux pumps in tigecycline resistance in KPCproducing Klebsiella pneumoniae. PLoS ONE 10:e119064. doi: 10.1371/journal. pone. 0119064

Hellmich, U. A., Lyubenova, S., Kaltenborn, E., Doshi, R., van Veen, H. W., Prisner, T. F., et al. (2012). Probing the ATP hydrolysis cycle of the ABC multidrug transporter LmrA by pulsed EPR spectroscopy. J. Am. Chem. Soc. 134, 5857-5862. doi: 10.1021/ja211007t

Higgins, C. F. (2001). ABC transporters: physiology, structure and mechanisman overview. Res. Microbiol. 152, 205-210. doi: 10.1016/S0923-2508(01) 01193-7

Hollenstein, K., Dawson, R. J., and Locher, K. P. (2007). Structure and mechanism of ABC transporter proteins. Curr. Opin. Struct. Biol. 17, 412-418. doi: 10.1016/ j.sbi.2007.07.003

Hu, V. H., Harding-Esch, E. M., Burton, M. J., Bailey, R. L., Kadimpeul, J., and Mabey, D. C. (2010). Epidemiology and control of trachoma: systematic review. Trop. Med. Int. Health 15, 673-691. doi: 10.1111/j.1365-3156.2010.02521.x

Hurlimann, L. M., Corradi, V., Hohl, M., Bloemberg, G. V., Tieleman, D. P., and Seeger, M. A. (2016). The Heterodimeric ABC Transporter EfrCD mediates multidrug efflux in Enterococcus faecalis. Antimicrob. Agents Chemother. 60, 5400-5411. doi: 10.1128/AAC.00661-16

Jones, P. M., and George, A. M. (1999). Subunit interactions in ABC transporters: towards a functional architecture. FEMS Microbiol. Lett. 179, 187-202. doi: 10.1111/j.1574-6968.1999.tb08727.x

Lancaster, H., Bedi, R., Wilson, M., and Mullany, P. (2005). The maintenance in the oral cavity of children of tetracycline-resistant bacteria and the genes encoding such resistance. J. Antimicrob Chemother. 56, 524-531. doi: 10.1093/jac/dki259

Lee, E.-W., Huda, M. N., Kuroda, T., Mizushima, T., and Tsuchiya, T. (2003). EfrAB, an $\mathrm{ABC}$ multidrug efflux pump in Enterococcus faecalis. Antimicrob. Agents Chemother. 47, 3733-3738. doi: 10.1128/AAC.47.12.3733-3738.2003

Levy, S. B., McMurry, L. M., Barbosa, T. M., Burdett, V., Courvalin, P., Hillen, W., et al. (1999). Nomenclature for new tetracycline resistance determinants. Antimicrob. Agents Chemother. 43, 1523-1524.

Lin, S. Y., Huang, C. H., Ko, W. C., Chen, Y. H., and Hsueh, P. R. (2016). Recent developments in antibiotic agents for the treatment of complicated intra-abdominal infections. Expert Opin. Pharmacother. 17, 339-354. doi: 10. 1517/14656566.2016.1122756

Linkevicius, M., Sandegren, L., and Andersson, D. I. (2015). Potential of tetracycline resistance proteins to evolve tigecycline resistance. Antimicrob Agents Chemother. 60, 789-796. doi: 10.1128/aac.02465-15

Liu, Y. Y., Wang, Y., Walsh, T. R., Yi, L. X., Zhang, R., Spencer, J., et al. (2016). Emergence of plasmid-mediated colistin resistance mechanism MCR-1 in animals and human beings in China: a microbiological and molecular biological study. Lancet Infect Dis. 16, 161-168. doi: 10.1016/S1473-3099(15)00424-7

Lubelski, J., Mazurkiewicz, P., van Merkerk, R., Konings, W. N., and Driessen, A. J. M. (2004). ydaG and ydbA of Lactococcus lactis encode a heterodimeric ATP-binding cassette-type multidrug transporter. J. Biol. Chem. 279, 3444934455. doi: 10.1074/jbc.M404072200

Lupien, A., Gingras, H., Leprohon, P., and Ouellette, M. (2015). Induced tigecycline resistance in Streptococcus pneumoniae mutants reveals mutations in ribosomal proteins and rRNA. J. Antimicrob. Chemother. 70, 2973-2980. doi: 10.1093/jac/ dkv211

Martinez, J. L. (2009). Environmental pollution by antibiotics and by antibiotic resistance determinants. Environ. Pollut. 157, 2893-2902. doi: 10.1016/j.envpol. 2009.05.051

McDaniel, C., Su, S., Panmanee, W., Lau, G. W., Browne, T., Cox, K., et al. (2016). A putative $\mathrm{ABC}$ transporter permease is necessary for resistance to acidified nitrite and EDTA in Pseudomonas aeruginosa under aerobic and anaerobic planktonic and biofilm conditions. Front. Microbiol. 7:291. doi: 10.3389/fmicb. 2016.00291
Mediavilla, J. R., Patrawalla, A., Chen, L., Chavda, K. D., Mathema, B., Vinnard, C., et al. (2016). Colistin- and carbapenem-resistant Escherichia coli harboring $m c r-1$ and $b l a_{\mathrm{NDM}-5}$, causing a complicated urinary tract infection in a patient from the United States. MBio 7, e01191-e01216 doi: 10.1128/mBio.01191-16

Olson, M. W., Ruzin, A., Feyfant, E., Rush, T. S. III, O'Connell, J., and Bradford, P. A. (2006). Functional, biophysical, and structural bases for antibacterial activity of tigecycline. Antimicrob. Agents Chemother. 50, 2156-2166. doi: 10. 1128/AAC.01499-05

Ramakrishnan, C., Dani, V. S., and Ramasarma, T. (2002). A conformational analysis of Walker motif A [GXXXXGKT (S)] in nucleotide-binding and other proteins. Protein Eng. 15, 783-798. doi: 10.1093/protein/15.10.783

Ramos, M. M. B., Gartti-Jardim, E. C., and Gaetti-Jardim Junior, E. (2009). Resistance to tetracycline and ${ }^{2}$-lactams and distribution of resistance markers in enteric microorganisms and pseudomonads isolated from the oral cavity. J. Appl. Oral Sci. 17, 13-18. doi: 10.1590/S1678-77572009000700004

Roberts, M. C. (2003). Tetracycline therapy: update. Clin. Infect. Dis. 36, 462-467. doi: $10.1086 / 367622$

Rubinstein, E., and Vaughan, D. (2005). Tigecycline: a novel glycylcycline. Drugs 65, 1317-1336. doi: 10.2165/00003495-200565180-00009

Sanger, F., Nicklen, S., and Coulson, A. R. (1977). DNA sequencing with chainterminating inhibitors. Proc. Natl. Acad. Sci. U.S.A. 74, 5463-5467. doi: 10.1073/ pnas.74.12.5463

Segata, N., Haake, S. K., Mannon, P., Lemon, K. P., Waldron, L., Gevers, D., et al. (2012). Composition of the adult digestive tract bacterial microbiome based on seven mouth surfaces, tonsils, throat and stool samples. Genome Biol. 13:R42. doi: 10.1186/gb-2012-13-6-r42

Seville, L. A., Patterson, A. J., Scott, K. P., Mullany, P., Quail, M. A., Parkhill, J., et al. (2009). Distribution of tetracycline and erythromycin resistance genes among human oral and fecal metagenomic DNA. Microb. Drug Resist. 15, 159-166. doi: $10.1089 / \mathrm{mdr} .2009 .0916$

Shen, F., Han, Q., Xie, D., Fang, M., Zeng, H., and Deng, Y. (2015). Efficacy and safety of tigecycline for the treatment of severe infectious diseases: an updated meta-analysis of RCTs. Int. J. Infect. Dis. 39, 25-33. doi: 10.1016/j.ijid.2015. 08.009

Someya, Y., Yamaguchi, A., and Sawai, T. (1995). A novel glycylcycline, 9-(N,Ndimethylglycylamido)-6-demethyl-6-deoxytetracycline, is neither transported nor recognized by the transposon Tn10-encoded metal-tetracycline/H+ antiporter. Antimicrob. Agents Chemother. 39, 247-249. doi: 10.1128/AAC.39. 1.247

Torres, C., Galian, C., Freiberg, C., Fantino, J. R., and Jault, J. M. (2009). The YheI/YheH heterodimer from Bacillus subtilis is a multidrug ABC transporter. Biochim. Biophys. Acta 1788, 615-622. doi: 10.1016/j.bbamem.2008. 12.012

Vaara, M. (1993). Outer membrane permeability barrier to azithromycin, clarithromycin, and roxithromycin in gram-negative enteric bacteria. Antimicrob. Agents Chemother. 37, 354-356. doi: 10.1128/AAC.37. 2.354

Van Berkel, M. A., Twilla, J. D., and England, B. S. (2016). Emergency department management of a myasthenia gravis patient with communityacquired pneumonia: does initial antibiotic choice lead to cure or crisis? J. Emerg. Med. 50, 281-285. doi: 10.1016/j.jemermed.2015.04.019

Villa, L., Feudi, C., Fortini, D., Garcia-Fernandez, A., and Carattoli, A. (2014). Genomics of KPC-producing Klebsiella pneumoniae sequence type 512 clone highlights the role of RamR and ribosomal S10 protein mutations in conferring tigecycline resistance. Antimicrob. Agents Chemother. 58, 1707-1712. doi: 10. 1128/aac.01803-13

Villedieu, A., Diaz-Torres, M. L., Hunt, N., McNab, R., Spratt, D. A., Wilson, M., et al. (2003). Prevalence of tetracycline resistance genes in oral bacteria. Antimicrob. Agents Chemother. 47, 878-882. doi: 10.1128/AAC.47.3.878-882. 2003

Warburton, P. J., Ciric, L., Lerner, A., Seville, L. A., Roberts, A. P., Mullany, P., et al. (2013). TetAB46, a predicted heterodimeric ABC transporter conferring tetracycline resistance in Streptococcus australis isolated from the oral cavity. J. Antimicrob. Chemother. 68, 17-22. doi: 10.1093/jac/dks351

Wu, N., Qiao, M., Zhang, B., Cheng, W. D., and Zhu, Y. G. (2010). Abundance and diversity of tetracycline resistance genes in soils adjacent to representative swine feedlots in China. Environ. Sci. Technol. 44, 6933-6939. doi: 10.1021/es1007802 
Yang, W., Moore, I. F., Koteva, K. P., Bareich, D. C., Hughes, D. W., and Wright, G. D. (2004). TetX is a flavin-dependent monooxygenase conferring resistance to tetracycline antibiotics. J. Biol. Chem. 279, 52346-52352. doi: 10.1074/jbc. M409573200

Yao, X., Doi, Y., Zeng, L., Lv, L., and Liu, J.-H. (2016). Carbapenem-resistant and colistin-resistant Escherichia coli co-producing NDM-9 and MCR-1. Lancet Infect. Dis. 16, 288-289. doi: 10.1016/S1473-3099(16)00057-8

Zheng, X., Freeman, A. F., Villafranca, J., Shortridge, D., Beyer, J., Kabat, W., et al. (2004). Antimicrobial susceptibilities of invasive pediatric Abiotrophia and Granulicatella isolates. J. Clin. Microbiol. 42, 4323-4326. doi: 10.1128/JCM.42. 9.4323-4326.2004

Zhong, X., Xu, H., Chen, D., Zhou, H., Hu, X., and Cheng, G. (2014). First emergence of acr $\mathrm{AB}$ and oqx $\mathrm{AB}$ mediated tigecycline resistance in clinical isolates of Klebsiella pneumoniae pre-dating the use of tigecycline in a Chinese hospital. PLoS ONE 9:e115185. doi: 10.1371/journal.pone.0115185

Conflict of Interest Statement: The authors declare that the research was conducted in the absence of any commercial or financial relationships that could be construed as a potential conflict of interest.

Copyright (๑ 2016 Reynolds, Roberts and Anjum. This is an open-access article distributed under the terms of the Creative Commons Attribution License (CC BY). The use, distribution or reproduction in other forums is permitted, provided the original author(s) or licensor are credited and that the original publication in this journal is cited, in accordance with accepted academic practice. No use, distribution or reproduction is permitted which does not comply with these terms. 